\title{
Mapeamento Tecnológico: uma prospecção de patentes e trabalhos científicos relacionados à própolis verde
}

\author{
Technological Mapping: a prospect of patents and scientific works \\ related to green propolis
}

\author{
Edgar Rodrigues de Araujo Neto ${ }^{1}$ \\ Lucas da Silva Morais ${ }^{1}$ \\ Ana Flávia Santos da Cunha ${ }^{2}$ \\ ${ }^{1}$ Universidade Federal Rural do Semi-Árido, Mossoró, RN, Brasil \\ ${ }^{2}$ Universidade Tiradentes, Aracaju, SE, Brasil
}

\begin{abstract}
Resumo
Com o crescimento de produtos naturais no mercado, a própolis verde obteve destaque, tornando-se, assim, necessário um estudo prospectivo do que já existe na área acadêmica e em bancos de patentes. O objetivo deste trabalho é apresentar o mapeamento tecnológico de patentes e trabalhos científicos relacionados à própolis verde. A metodologia adotada foi o mapeamento utilizando-se as bases de dados do Instituto Nacional da Propriedade Industrial (INPI) e do Worldwide Patent Database (Espacenet) para patentes e do Google acadêmico, da Biblioteca Digital Brasileira de Teses e Dissertações (DBTD) e do Web of Science para trabalhos científicos, utilizando-se a busca por palavras-chave no corpo dos textos. Os dados indicaram duas patentes no INPI e 10 na Espacenet, a China como maior depositante e o ano de 2017 com mais depósitos. No científico, foram 47 na BDTD, 2.765 no Google acadêmico, 206 no Web of Science e o ano de 2017 com mais registros.
\end{abstract}

Palavras-chave: Trabalhos Científicos. Patentes. Própolis Verde.

\begin{abstract}
With the growth of natural products in the market, the green propolis highlighted, thus making necessary a prospective study of what already exists in the academic area and in patent banks. The objective of this work was to present the technological mapping of patents and scientific works related to green propolis. The methodology adopted was the mapping using the databases of National Institute of Industrial Property (INPI) and Worldwide Patent Database (Espacenet) for patents and Google academic, Brazilian Digital Library of Theses and Dissertations (DBTD) and Web of Science for scientific works, using the search for keywords in the texts. The data indicated 2 patents in the INPI and 10 in the Espacenet, China as the largest depositor, 2017 as year with more deposits. In scientific terms there were 47 in the BDTD, 2765 in Google academic and 206 in the Web of Science, 2017 as year with more registrations.
\end{abstract}

Keywords: Scientific Work. Patents. Green Propolis.

Área Tecnológica: Farmacêutica. Tecnologia. 


\section{Introdução}

Os primeiros relatos de utilização de própolis foram encontrados no Egito antigo e na Mesopotâmia, porém já se sabe que foi muito utilizada por diferentes civilizações como a dois gregos, romanos, assírios e outros. Sua utilização foi observada no papiro escrito por Ebers em 1700 a.C e nos processos de mumificação durante o embalsamento dos mortos no antigo Egito (FUNARI; FERRO, 2006; PINTO; PRADO; CARVALHO, 2011).

A partir da década de 1980 é possível observar um crescimento da utilização da própolis, seja com fins alimentícios ou medicinais, observando-se assim em paralelo o crescimento de estudos relacionados ao tema. Esse cenário da década de oitenta foi onde se criou o mercado internacional para a própolis, a qual chegou a ser cotada entre US\$ 80 e 100 o kg do produto in natura (FUNARI; FERRO, 2006).

Com o crescimento rápido de mercado e maiores exigências por parte dos consumidores, empresas de diferentes nacionalidades tendem a investir em desenvolvimento tecnológico buscando soluções inovadoras e mantendo, assim, sua competição no mercado atual (FRAGA et al., 2017; SILVA; UCHÔA; TONHOLO, 2016).

Atualmente observa-se um aumento no uso de produtos apícolas e, entre eles, a própolis vem se destacando. A própolis geralmente é composta de uma mistura complexa de substâncias, $50 \%$ de resina e bálsamo, $30 \%$ de cera, $10 \%$ de óleos essenciais e aromáticos, $5 \%$ de pólen e $5 \%$ de várias outras substâncias, possuindo consistência, textura e coloração variada (PINTO; PRADO; CARVALHO, 2011; SILVA et al., 2006). Já a sua composição química se apresenta como bastante complexa possuindo mais de 160 componentes, e entre os identificados vale ressaltar os flavonóides (flavonas, flavolonas e flavononas), ácido benzoico, álcool cinâmico, ácido cafeico, chalconas, ácidos diterpenos e triterpenos, álcoois, heteroaromáticos, benzaldeídos, fenólicos, cetonas, minerais e outros (PINTO et al., 2001). Essa complexa composição química é o que vem chamando a atenção das indústrias farmacêuticas e alimentícias para o estudo da própolis em qualquer uma das suas variações, tornando-se necessário cada vez mais os estudos e a identificação dos mais diversos tipos de própolis espalhadas pelas regiões do Brasil.

Porém, a própolis brasileira se divide em 12 tipos, levando-se em conta as características físico-químicas, oriundas da grande variabilidade da flora brasileira (FERREIRA; NEGRI, 2018; PARLK; IKEGAKI; ALENCAR, 2000). Pode possuir aromas característicos, grande variação de coloração (de amarelada a pardo escuro) e sabores variados (suave a forte, amargo e picante) (PINTO et al., 2001).

Entre todas as própolis brasileiras, é possível afirmar que as principais são a verde e a vermelha, as quais possuem uma distinta composição química devido às suas plantas de origem, porém apresentando ambas os princípios ativos que exercem as funções farmacológicas (FERREIRA; NEGRI, 2018). Há diversos estudos relacionado à própolis vermelha, inclusive artigos relacionados à prospecção tecnológica, como encontrados em Fraga et al. (2017) e Silva, Uchôa e Tonholo (2016).

A própolis verde é um produto endêmico de várias regiões do Brasil, e sua diferença está na sua composição floral, a qual tem origem nos brotos dos arbustos de alecrim-do-campo (Baccharis dracunculifolia), sendo bastante produzida nas regiões Sul, Leste, Centro e Zona da Mata de Minas Gerais, Leste de São Paulo, Norte do Paraná e em regiões serranas do Espírito 
Santo e Rio de Janeiro. Com o seu eficaz combate microbiano, ela se tornou bastante valorizada no mercado externo, tendo com principal comprador o Japão (MARTINEZ; SOARES, 2012). Mais uma vez, afirma-se a necessidade de estudo e de proteção no produto nacional, garantindo assim ao país o direito legal sobre o produto (Própolis verde) e a todos os seus subprodutos oriundos de processos, seja de produção (coletores de própolis) ou de extrações de compostos específicos.

O presente trabalho tem como objetivo realizar o mapeamento tecnológico por meio de documentos de patentes depositadas e publicações de artigos científicos relacionados à própolis verde, trazendo assim uma real perspectiva do atual nível tecnológico e acadêmico e possibilitando o andamento de futuros trabalhos relacionados ao tema.

\section{Metodologia}

A presente metodologia se divide em cinco etapas. Sendo a primeira a responsável pela busca por documentos de patentes nas plataformas do Instituto Nacional da Propriedade Industrial (INPI) e Worldwide Patent Database (Espacenet). A segunda etapa foi a busca por artigos científicos utilizando o Google acadêmico, a Biblioteca Digital Brasileira de Teses e Dissertações (DBTD) e a Web of Science. Para a terceira etapa foram novamente utilizados os dados do Instituto Nacional da Propriedade Industrial (INPI), tendo em vista a busca por pedidos de indicação geográfica. Utilizando a quarta etapa foi possível efetuar a estratégia de busca, selecionando as palavras-chave e os conectores booleanos de interesse. Por fim, todos os resultados obtidos foram exportados para o software Microsoft Office Excel 2010, permitindo, assim, a realização da quinta e última etapa, que é a análise dos dados.

\subsection{Busca por Documentos de Patentes}

Para o mapeamento prospectivo foram avaliados os pedidos de patentes depositados no banco de dados on-line do Instituto Nacional da Propriedade Industrial (INPI) tendo em vista a abrangência de todas as patentes depositadas e publicadas em território nacional. Para a busca internacional foi utilizada a base de dados on-line Worldwide Patent Database (Espacenet), a qual possui uma coleção completa dos pedidos de patentes publicados em mais de 90 países. As buscas de patentes foram realizadas no período de 2011 a 2019.

\subsection{Busca por Artigos Científicos}

A prospecção em bases acadêmicas foi feita utilizando-se as bases de dados on-line Google acadêmico, Biblioteca Digital Brasileira de Teses e Dissertações (DBTD) e Web of Science. A utilização de três bases foi adotada para obter uma maior abrangência de resultados. As buscas acadêmicas foram realizadas no período de 2009 a 2019. 


\title{
2.3 Busca por pedidos de indicação geográfica
}

Levando-se em consideração a regionalidade da própolis verde, foi utilizado o sistema de busca do Instituto Nacional da Propriedade Industrial (INPI) para registrar a presença de pedidos de indicação geográfica da própolis verde.

\subsection{Estratégia de Busca}

A estratégia de busca utilizada em todas as bases de dados (Patentes e Acadêmicas) foi a utilização de conectores booleanos e palavras-chave (Tabela 1), sempre selecionando os parâmetros de buscas para o Título e Resumo. A utilização do booleano ("”) se fez necessária devido à abrangência das palavras-chave. Como exemplo, cita-se o Green Propolis, que, quando pesquisado sem o booleano, obteve resultados relacionados a pesquisas e patentes com Green Tea, justificando-se assim a necessidade da utilização dos booleanos.

Tabela 1 - Escopo da estratégia de busca por patentes relacionadas ao uso da própolis verde

\section{MAPA DE Busca}

\author{
Conceito Principal: Própolis verde \\ Palavras-chave \\ "Própolis verde" \\ "Green Propolis" \\ "Própolis verde brasileira" \\ "Brazilian green propolis"
}

Fonte: Elaborada pelos autores deste artigo (2019)

\subsection{Análise dos Dados}

Todos os resultados obtidos foram exportados para o software Microsoft Office Excel 2010, possibilitando organizar os dados e visualizar as análises procuradas. Foram analisados a distribuição anual de patentes e artigos científicos, os países com mais depósitos de patentes, os códigos de classificação, averiguando-se classe e subclasses encontradas nos documentos, os principais investidores e os pedidos de indicação geográfica. Todos os resultados encontrados foram apresentados na forma de gráficos e tabelas.

\section{Resultados e Discussão}

A busca por patentes na base nacional (INPI) obteve dois registros de documentos de patentes relacionados à própolis verde. Para a busca na base internacional (Espacenet) foram obtidos 10 registros de documentos de patentes relacionados ao tema (Tabela 2). 
Tabela 2 - Pedidos de patentes depositadas no INPI e no Espacenet de acordo com as palavras-chave

\begin{tabular}{ccc} 
& INPI & ESPACENET \\
"Própolis verde" & 2 & 0 \\
"Green Propolis" & 0 & 7 \\
"Própolis verde brasileira" & 0 & 0 \\
"Brazilian green propolis" & 0 & 3 \\
Total & 2 & 10 \\
\hline
\end{tabular}

Fonte: Elaborada pelos autores deste artigo (2019)

Os depósitos demonstram que, apesar de o Brasil possuir um bom potencial de produção de própolis verde, ainda há um déficit em depósitos de patentes, pois de 12 documentos de patentes, apenas dois são de propriedade nacional. Segundo Pereira, Seixas e Aquino Neto (2002), apesar das condições propícias do Brasil em relação à produção de própolis, se comparado a países como Japão, ainda não apresenta o mesmo interesse tecnológico relacionado à própolis. Segundo Machado et al. (2012), a primeira patente nacional relacionada à própolis foi depositada em 1994 (BR94042861) em Minas Gerais, a qual tinha como função proteger um processo de preparação de um creme contendo própolis triturado. Esse depósito ocorreu 26 anos depois do primeiro depósito de patente relacionado à própolis. Tal pedido foi de autoria japonesa (JP92033270), confirmando, assim, o atraso do Brasil em relação aos depósitos de patentes relacionados à própolis, não ocorrendo de forma diferente com a própolis verde.

Para as buscas nas bases acadêmicas foram encontradas 42 teses e dissertações na Biblioteca Digital Brasileira de Teses e Dissertações (BDTD), 2.765 artigos científicos no Google Acadêmico e 206 artigos científicos na Web of Science, todos relacionados à própolis verde (Tabela 3).

Tabela 3 - Número de artigos publicados nas bases acadêmicas de acordo com as palavras-chave

\begin{tabular}{cccc} 
& BDTD & Google AcadÊMico & WeB OF Science \\
"Própolis verde" & 49 & 654 & 15 \\
"Green Propolis" & 53 & 2.701 & 145 \\
"Própolis verde brasileira" & 2 & 102 & 1 \\
"Brazilian green propolis" & 9 & 1.896 & 76 \\
Total & 113 & 5.353 & 237 \\
\hline
\end{tabular}

Fonte: Elaborada pelos autores deste artigo (2019)

Se comparadas as duas tabelas anteriores, pode-se observar a discrepância de artigos publicados em relação ao número de registro de patentes. Essa diferença está ligada a fatores como: trabalhos relacionados à biologia da produção da própolis verde, estudos que não são patenteáveis e desconhecimento dos processos de patenteamento, podendo-se assim observar que, apesar de poucos registros de patentes, já existe um interesse do meio científico em relação ao estudo da própolis verde.

Quando comparados os números das três bases de pesquisa, é possível observar a diferença dos resultados encontrados entre a BDTD e as outras duas bases. Essa diferença ocorre porque 
a BDTD é uma plataforma exclusivamente de teses e dissertações das universidades federais do Brasil, não constando nela os artigos científicos oriundos dos trabalhos científicos, porém, demonstra o interesse das instituições sobre a própolis verde.

Quando observada a distribuição anual dos documentos de patentes relacionadas à própolis verde (Figura 1) verifica-se o primeiro registro brasileiro em 2012 e o segundo só em 2014. Quando se observa o cenário internacional, os primeiros registros ocorreram em 2011, mantendo-se uma constância de um registro anual até 2013. Durante o período avaliado, apenas o ano 2014 não apresentou registros de documentos de patentes, e o ano com maior registro foi 2017 com três registros de documentos de patentes.

Figura 1 - Evolução anual do depósito de patentes

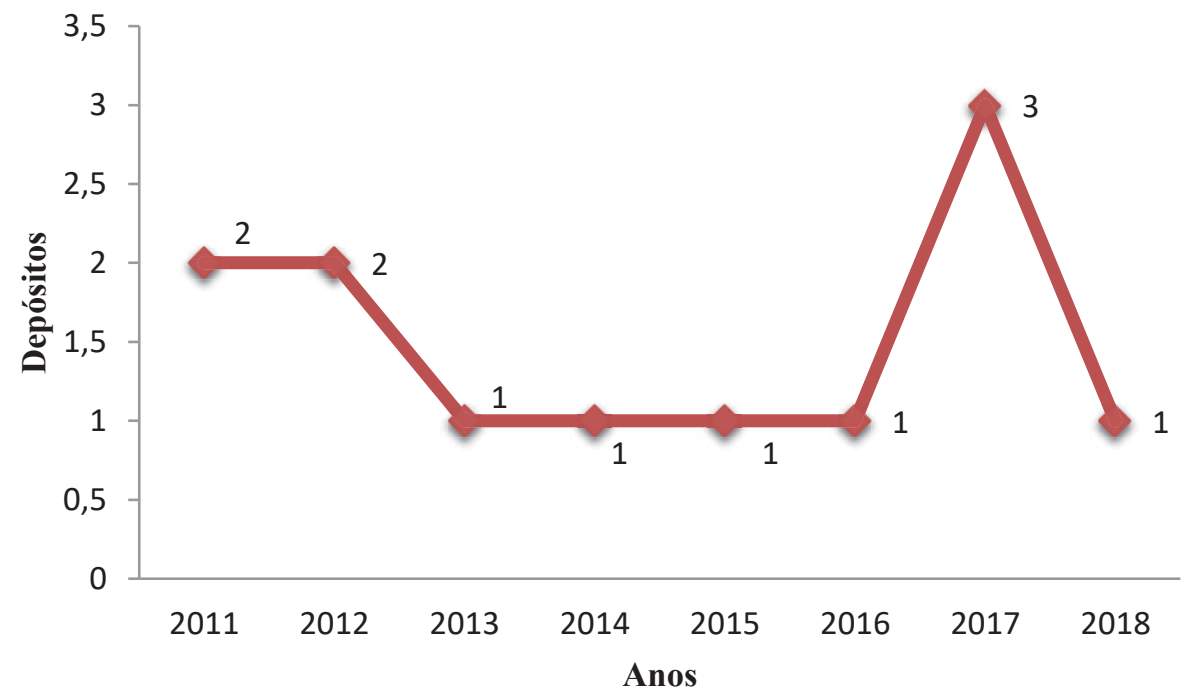

Fonte: Elaborada pelos autores deste artigo (2019)

Em comparação ao cenário da prospecção da própolis vermelha demonstrado por Fraga et al. (2017), os dados diferem não só na quantidade de depósitos como no crescente número de depósitos, em que os depósitos de patentes relacionadas à própolis vermelha vêm crescendo desde 2011, chegando ao número de 45 depósitos em 2015 e tendo apenas um decrescimento em 2016, decréscimo esse que pode ser justificado pelo ano de publicação do artigo, tendo que se levar em conta o período de sigilo do pedido. Os dados demonstram que, apesar de uma constância nos depósitos de patentes relacionadas à própolis verde, ainda existe uma grande diferença, se comparados aos depósitos relacionados à própolis vermelha.

A distribuição anual de artigos científicos (Figura 2) obteve uma média de 514,2 trabalhos científicos por ano, tendo 2017 como o ano de maior produção científica, tanto no Google Acadêmico como na Web of Science. Já as dissertações e teses obtiveram uma média anual de 9,4 trabalhos por ano, diferentemente dos artigos científicos, cujo ano com mais trabalhos relacionados à própolis verde foi 2015, com 20 trabalhos relacionados ao tema (Tabela 2). 
Figura 2 - Distribuição anual de artigos científicos

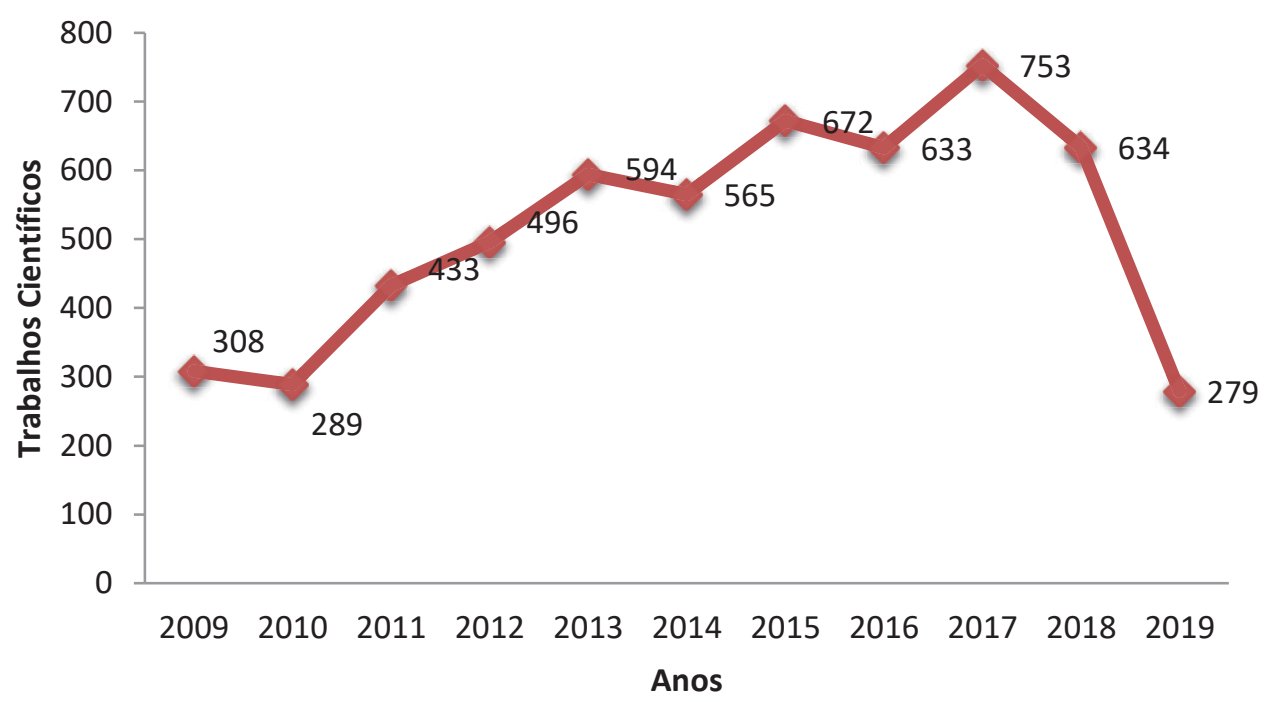

Fonte: Elaborada pelos autores deste artigo (2019)

Verificando-se as médias anuais dos trabalhos científicos é possível reafirmar o interesse da própolis verde no meio científico, valendo ressaltar que a própolis, seja verde ou não, é um assunto interdisciplinar, transitando nas mais diversas áreas, indo da zootecnia (Produção) $e$ economia (Comercio) até a farmacologia (Estudo de compostos) e medicina (Aplicação). Essa variedade de áreas está associada à diferença entre o número de trabalhos e o número depósitos de patentes, já que boa parte dos trabalhos científicos só geram artigos científicos e não produtos ou técnicas patenteáveis.

A Figura 3 apresenta os dados relacionados à análise quanto aos países nos quais se originaram os registros de patentes, e demonstra que a maior parte das patentes relacionadas à própolis verde foi depositada pela China (cinco patentes), representando, assim, 41,66\% das patentes encontradas. Em segundo lugar, pode-se observar Brasil e Taiwan, ambos com duas patentes, equivalendo, assim, a 16,66\% cada.

Figura 3 - Depósitos de Patentes por Países

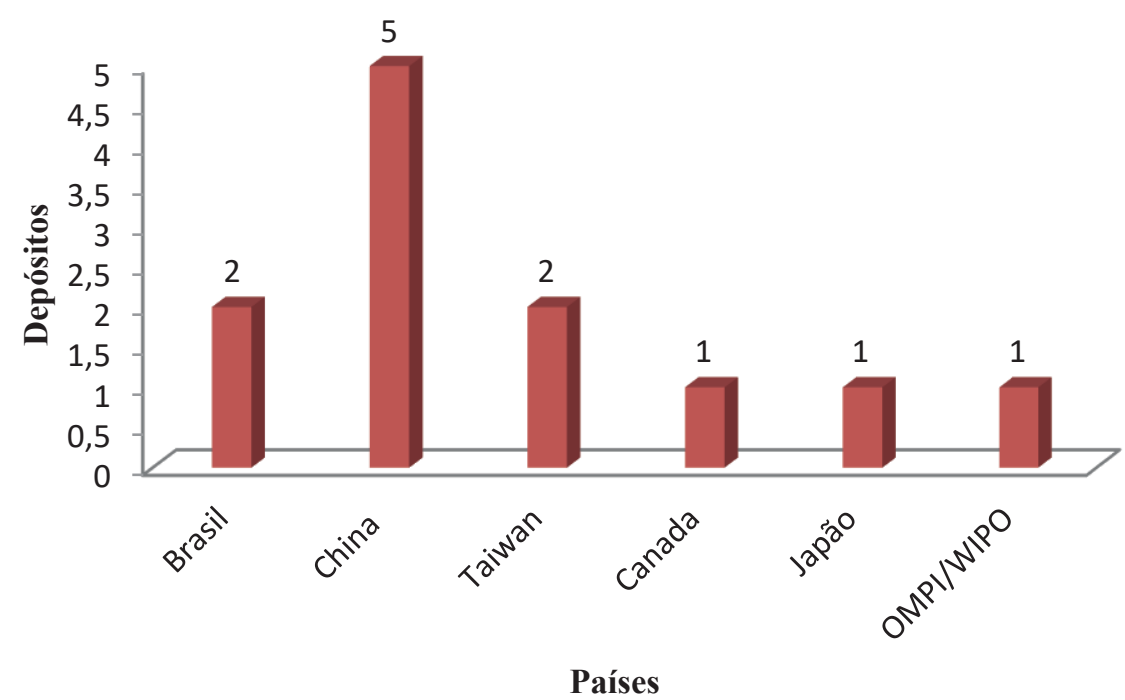

Fonte: Elaborada pelos autores deste artigo (2019) 
A primeira colocação da China em depósitos corrobora com os dados encontrados por Fraga et al. (2017), os quais, apesar de tratarem de própolis vermelha, indicam a China como o país com o maior número de depósitos, demonstrando assim um interesse chinês em produtos oriundos da própolis, tanto a verde como a vermelha.

Com os dados encontrados foi possível observar o perfil das instituições depositantes (Figura 4), demonstrando assim um maior interesse de empresas privadas (nove registros) no depósito de patentes quando comparadas com os depósitos feitos por universidades (três registros). Estes números maiores de registros por empresas estão associados aos interesses econômicos ligados às patentes.

Figura 4 - Perfil dos Depositantes

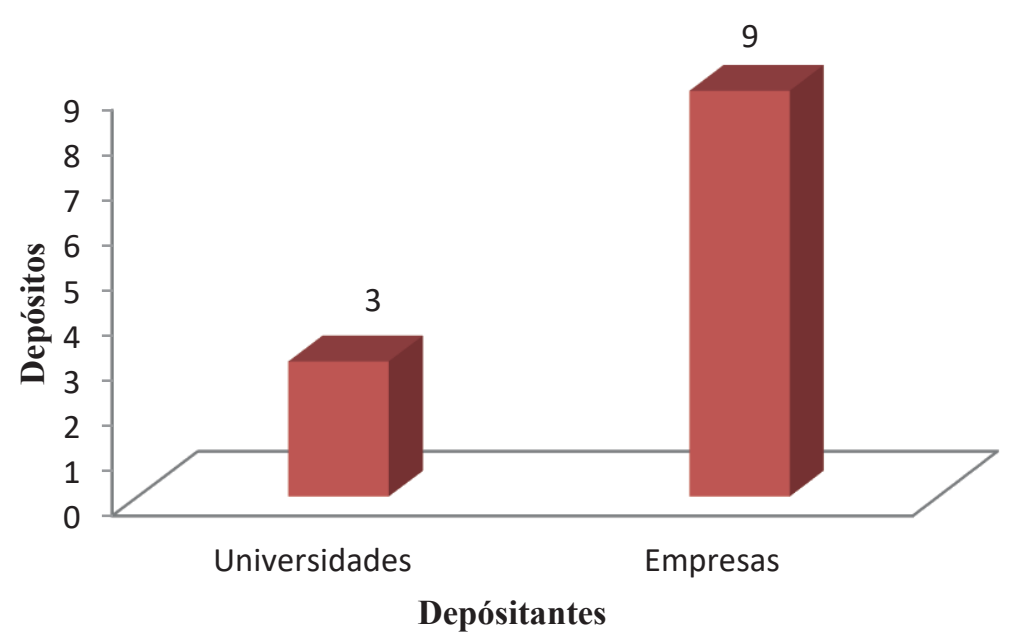

Fonte: Elaborada pelos autores deste artigo (2019)

Segundo Machado et al. (2012), a causa de as universidades possuírem um menor número de depósitos está associada à falta de incentivos políticos e governamentais para estimular e articular as parcerias entre as iniciativas privadas (Empresas) e as públicas (Universidades) do país, gerando assim um cenário com poucas patentes relacionadas a área de pesquisa.

Foram verificadas quais as IPCs (Classificação Internacional de Patentes) que se encontram mais presentes nas patentes com o intuito de identificar as áreas de aplicação tecnológica dos documentos (Figura 5). A classe mais encontrada foi a A61K (25), a qual está relacionada a preparações para finalidades médicas, odontológicas ou higiênicas, sendo a classe A61P a segunda com maior repetição (12), classe esta associada à atividade terapêutica de compostos químicos ou preparações medicinais. 
Figura 5 - Classificação Internacional de Patentes

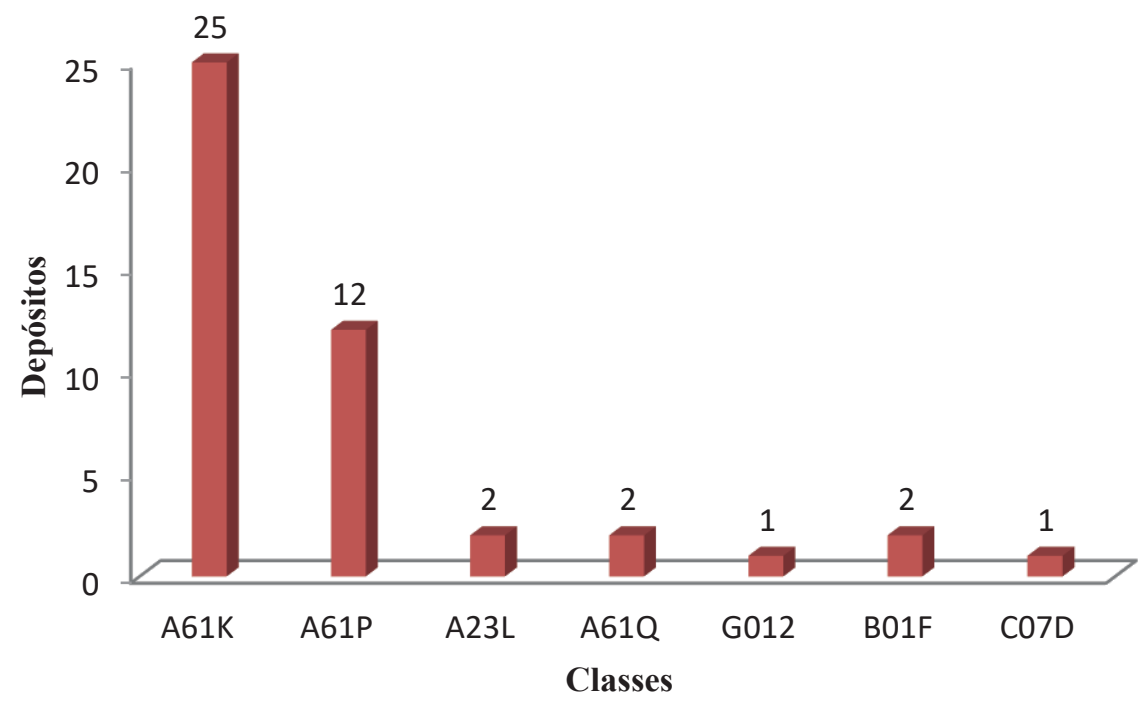

Fonte: Elaborada pelos autores deste artigo (2019)

Segundo Machado et al. (2012), é comum a Seção A ser a mais repetida em buscas com relação à própolis, devido à utilização principal da própolis estar ligada a aplicações farmacológicas e terapêuticas (Tabela 4). Os dados encontrados no presente trabalho corroboram com Machado et al. (2012), nos quais, apesar de não ter muitas repetições, também foram encontrados IPCs das seções C (Química e Metalurgia) e G (Física) em alguns documentos, demonstrando assim a proteção da própolis verde em diferentes áreas.

Tabela 4 - Classificação Internacional de Patentes

$\begin{array}{cc}\text { Código de ClassificaÇão } & \begin{array}{c}\text { Significado das CLASSificaçõES } \\ \text { A61K }\end{array} \\ \text { A61P } & \begin{array}{c}\text { Preparação para fins médicos, } \\ \text { dentários ou de higienização. }\end{array} \\ \text { A23L } & \begin{array}{c}\text { Atividade terapêutica específica de compostos } \\ \text { químicos ou preparações medicinais. }\end{array} \\ \text { A61Q } & \text { Alimentos e bebidas não alcóolicas. } \\ \text { Uso específico de cosméticos ou } \\ \text { preparação de itens de higienização. }\end{array}$

Fonte: Elaborada pelos autores deste artigo (2019)

Além das classes, as subclasses (Figura 6) que obtiveram destaque foram A61K 35/64 e A61K 35/644, reafirmando a repetição da Classe A em patentes relacionadas à própolis verde. 
Figura 6 - Distribuição dos resultados pelas subclasses da IPC

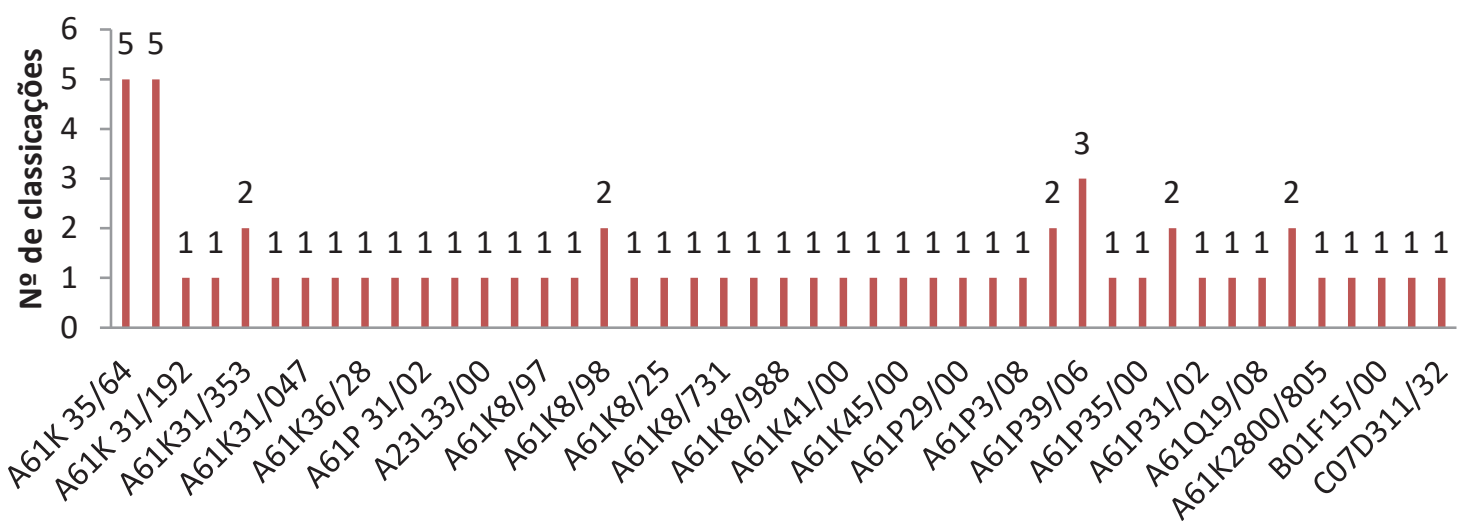

Classificação Internacional

Fonte: Elaborada pelos autores deste artigo (2019)

As subclasses A61K 35/64e A61K 35/644 estão diretamente ligadas às abelhas (Tabela 5).

Tabela 5 - Classificação Internacional de Patentes

$\begin{array}{cc}\text { Código dE SUBCLASSE } & \text { Significado DAS CLASSIFICAÇõES } \\ \text { A61K 35/64 } & \begin{array}{c}\text { Subclasse exclusiva para insetos como } \\ \text { abelhas, vespas ou pulgas. }\end{array} \\ \text { A61K 35/644 } & \begin{array}{c}\text { Subclasse voltada para produtos apícolas como } \\ \text { cera de abelha; própolis; geleia real e mel. }\end{array}\end{array}$

Fonte: Elaborada pelos autores deste artigo (2019)

Os dados demonstram o interesse que as indústrias têm em produtos apícolas, possuindo subclasses diretamente ligadas a esse nicho de mercado e, mais especificamente, no registro dos produtos oriundos da própolis verde.

Com a busca por registro de indicação geográfica por meio do INPI, foi encontrado apenas um registro (BR412013000005-4), de propriedade da Federação Mineira de Apicultura (FEMAP), localizada em Minas Gerais, tendo sua indicação geográfica como Região da Própolis Verde de Minas Gerais, a qual foi registrada em 2016 e tem como sua delimitação a "Região da Própolis Verde de Minas Gerais", compreendida entre as coordenadas 42050'24"W a 47²4'10"W de longitude e 18¹4'02"S a 22051'18"S de latitude e composta de 102 municípios.

O resultado da busca por indicação geográfica demonstra o desconhecimento destes registros pelos grandes grupos de pesquisa relacionados à própolis no Brasil, pois, como se pode observar em trabalhos como Ferreira e Negri (2018), Pereira, Seixas e Aquino Neto (2002) e outros, o país possui uma grande variedade de própolis, seja na cor (marrom, verde e vermelha) ou em sua vasta composição devido à variedade floral que aqui se encontra. Apenas Minas Gerais e Alagoas possuem suas própolis registradas quanto à sua indicação geográfica, sendo essas duas regiões as pioneiras na extração de própolis verde (Minas Gerais) e de própolis vermelha (Alagoas), sendo que essa diferenciação está diretamente associada a espécies de cada uma dessas regiões, deixando assim clara a necessidade de avaliação e proteção das própolis oriundas das mais diversas regiões do Brasil. 


\section{Considerações Finais}

A maior parte das patentes relacionadas à própolis verde está depositada fora do banco de dados nacional. O ano com maiores depósitos de patentes foi 2017, e o país que possui mais registros de patentes é China. Das patentes encontradas, $75 \%$ são de propriedade de empresas, e não de instituições de ensino; e quanto à classificação internacional, a classe A61K foi a mais encontrada.

A pesquisa nas bases científicas permitiu concluir que a base com maior número de trabalhos científicos foi o Google Acadêmico, sendo 2017 o ano com maior número de trabalhos científicos entre todas as bases pesquisadas. Vale ressaltar que o número inferior encontrado na BDTD está associado ao fato de ser uma base que hospeda apenas teses e dissertações concluídas, e não artigos publicados em periódicos ou congressos/simpósios.

Em relação ao pedido de identificação geográfica, foi possível concluir que existe apenas um pedido para a própolis verde, de propriedade da Federação Mineira de Apicultura (FEMAP), e está registrado como "Própolis Verde de Minas Gerais".

\section{Referências}

FERREIRA, J. M.; NEGRI, G. Composição química e atividade biológica das própolis brasileiras: verde e vermelha. ACTA Apicola Brasilica, [S.l.], v. 6, n. 1, p. 6-15, 2018.

FRAGA, É. E. A. et al. Prospecção tecnológica: um mapeamento de patentes da própolis vermelha. Cadernos de Prospecção, Salvador, v. 10, n. 3, p. 524-532, 2017.

FUNARI, C. S.; FERRO, V. O. Análise de própolis. Cienc. Tecnol. Aliment. [S.1.], v. 26, n. 1, p. 171-178, 2006.

MACHADO, B. A. S. et al. Estudo prospectivo da própolis e tecnologias correlatas sob o enfoque em documentos de patentes depositados no Brasil. Revista GEINTEC-Gestão, Inovação e Tecnologias, [S.l.], v. 2, n. 3, p. 221-235, 2012.

MARTINEZ, O. A.; SOARES, A. E. E. Melhoramento genético na apicultura comercial para produção da própolis. Revista Brasileira de Saúde e Produção Animal, [S.I.], v. 13, n. 4, p. 982-990, 2012.

PARLK, Y. K.; IKEGAKI, M.; ALENCAR, S. M. Classificação das própolis brasileira a partir de suas características físico-químicas e propriedades biológicas. Mensagem Doce, [S.l.], v. 58, n. 9, p. 2-7, 2000.

PEREIRA, A. S.; SEIXAS, F. R. M. S.; AQUINO NETO, F. R. Própolis: 100 anos de pesquisa e suas perspectivas futuras. Química Nova, [S.l.], v. 25, n. 2, p. 321-326, 2002.

PINTO, L. M. A.; PRADO, N. R. T.; CARVALHO. L, B. Propriedades, usos e aplicações da própolis. Revista Eletrônica de Farmácia, [S.1.], v. 8, n. 3. p. 76-100, 2011.

PINTO, M. S. et al. Efeito de extratos de própolis verde sobre bactérias patogênicas isoladas do leite de vacas com mastite. Brazilian Journal of Veterinary Research and Animal Science, [S.I.], v. 38 , n. 6, p. 278-283, 2001. 
SILVA, P. B.; UCHÔA, S. B. B.; TONHOLO, J. Mapeamento tecnológico da própolis vermelha do estado de alagoas - PVA. Cadernos de Prospecção, Salvador, v. 9, n. 1, p. 30-37, 2016.

SILVA, R. A. S. et al. Características físico-químicas e atividade antimicrobiana de extratos de própolis da Paraíba, Brasil. Ciência Rural, [S.l.], v. 36, n. 6, 2006.

\section{Sobre os Autores}

\section{Edgar Rodrigues de Araujo Neto}

E-mail:neto13br@gmail.com Mestre em Produção Animal.

Endereço profissional: UFERSA, Rua Francisco Mota Bairro, n. 572, Pres. Costa e Silva, Mossoró, RN. CEP: 59625-900.

\section{Lucas da Silva Morais}

E-mail: morais.lucas11@gmail.com

Mestre em Produção Animal.

Endereço profissional: UFERSA, Rua Francisco Mota Bairro, n. 572, Pres. Costa e Silva, Mossoró, RN. CEP: 59625-900.

\section{Ana Flávia Santos da Cunha}

E-mail: fsantoscunha23@gmail.com

Bacharel em Ciências Biológicas.

Endereço profissional: Universidade Tiradentes, Av. Murilo Dantas, n. 300, Farolândia, Aracaju, SE. CEP: 49032-490. 